\title{
J182011
}

\section{衝突時に電車内で着座している人体の転倒挙動を求める 模型実験とシミュレーション}

\author{
渋江唯司 ${ }^{* 1}$, 河辺和也 ${ }^{* 2}$, 速水尚 ${ }^{* 1}$, 澤井徹 ${ }^{* 1}$, 大政光史 ${ }^{* 1}$, 廣川敬康 ${ }^{* 1}$
Model experiments and a numerical simulation for the estimation of falling behavior of a seated passenger on the train at collision \\ Tadashi SHIBUE ${ }^{* 1}$, Kazuya KAWABE $^{1}$, Takashi HAYAMI $^{* 1}$, Toru SAWAI ${ }^{*}{ }^{1}$, Mitsushi OHMASA ${ }^{* 1}$ \\ and Noriyasu HIROKAWA ${ }^{* 1}$ \\ ${ }^{* 1}$ Kinki Univ. Dept. of Biomechanics and Human factors Engineering \\ Nishimitani 930, Kinokawa, Wakayama, 649-6493 Japan
}

\begin{abstract}
Studies based on the numerical simulation to understand the falling behavior of passengers on public transportation system have been carried out. Experimental verifications are necessary to understand the actual behavior and increase the accuracy of the simulation method. A carriage system on which a human body model can be seated is used and collision experiments are carried out under the very low speed of $0.21 \mathrm{~m} / \mathrm{s}$. The movement of the carriage and the human body are measured with high speed cameras. In addition, a numerical simulation of the experiment with FEM code LS-DYNA is carried out to see the estimation accuracy of both the simulation model and the simulation method.
\end{abstract}

Key Words : Experiment, Collision, Passenger, Train, Numerical simulation

\section{1. 緒言}

高齢化を背景に, バス・電車などの公共交通機関の重要性が高まりつつあり, 衝突などで衝撃を受けた際の安 全性に関する研究(1)が行われてきた．筆者らは，有限要素法を用いた数值シミュレーションにより衝突時のバス や電車などの公共交通機関内での転倒挙動の推定 ${ }^{(2)(3)}$ に取り組んできている.

本研究では通勤電車で多用されているロングシートに着座した人体の衝突時の挙動を, 有限要素法 LSDYNA ${ }^{(4)}$ を用いた数值シミュレーションによって再現するためのモデル作成法および解析上の技術を獲得す るための研究を行う. 研究の一環として, 数值シミュレーションの精度向上のために, 想定する衝突現象を 模擬した実験を行い, 計測された結果を数值シミュレーションの結果と比較して数值シミュレーション法の 精度確認を行う. 同時に実験により，ロングシートに着座した人体を支える肘掛や壁の有無による人体挙動 への影響を調べる.

\section{2. 実験}

\section{$2 \cdot 1$ 実験装置}

衝突時の電車内部のロングシート座席と人体を模擬する模型を台車に載せて走行させ障壁に衝突させて衝突時 の挙動を計測する. 実験は Fig.1 および Fig.2 に示すように, 実験室内部に設置した基礎上にレールを敷設し, 座 席と人体の模型を載せた縦 $2.0 \mathrm{~m}$, 横 $1.1 \mathrm{~m}$, レール面からの高さ $0.3 \mathrm{~m}$, 質量 $160 \mathrm{~kg}$ の台車を, 落鍾式の加速装置 で約 $0.25 \mathrm{~m} / \mathrm{s}$ の速度で基礎と一体化したストッパーに衝突させる. 衝突前後の動きを 2 台の高速度カメラで撮影 し, 画像解析を行って模型や台車各部の時閒变化を計測する. 使用する高速度カメラは HotShot1280 で, 解像度 は 1280x1080 ピクセルのモードで 250 フレーム/秒の速度で撮影を行い, モーションキャプチャーソフトで 3 次元

\footnotetext{
${ }^{{ }^{*} 1}$ 正員, 近畿大学 (广 649-6493 和歌山県紀の川市西三谷 930) ${ }^{*^{*} 2}$ 近畿大学

E-mail: shibue@waka.kindai.ac.jp
}

[No.13-1] 日本機械学会 2013 年度年次大会講演論文集 [2013.9.8-11, 岡山 $]$ 
的な動きの解析を行う.

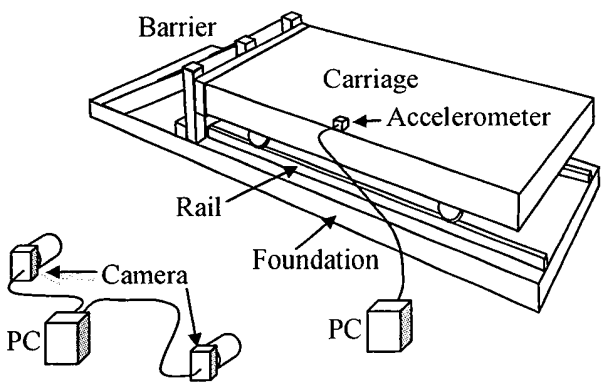

Fig.1 Experiment set up

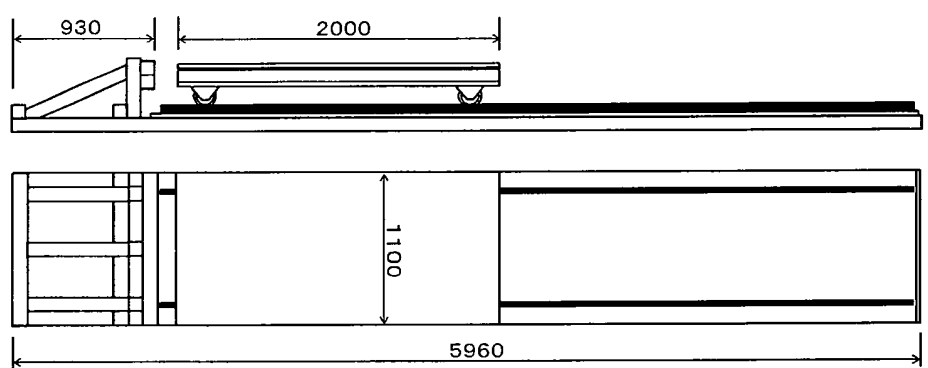

Fig.2 Major sizes of a carriage and a foundation with a barrier

\section{$2 \cdot 2$ 実験用椅子および人体の模型}

実験用の椅子は，南海電鉄で使用されている通勤用車両のロングシートの形状をもとに，木材（厚さ $30 \mathrm{~mm} の$ 構造用合板）をボルトで結合して作成し，実験時には台車上にボルトで固定して使用する．Fig.3に示すように， 椅子の端部に肘掛がないもの $(\mathbf{N})$ ，肘掛を持つもの (A)，および肘掛の代わりに大きな板を取り付け壁を模擬し たもの (W) の 3 種類を実験に用い，図中に○印で示す台車，人体頭部の動きを測定して，転倒に及ぼす肘掛や 壁の影響も調べる.

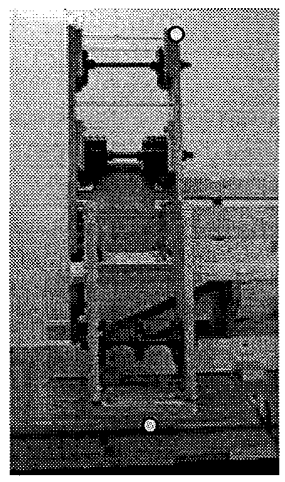

(a) Side \& rear views of the case without armrest

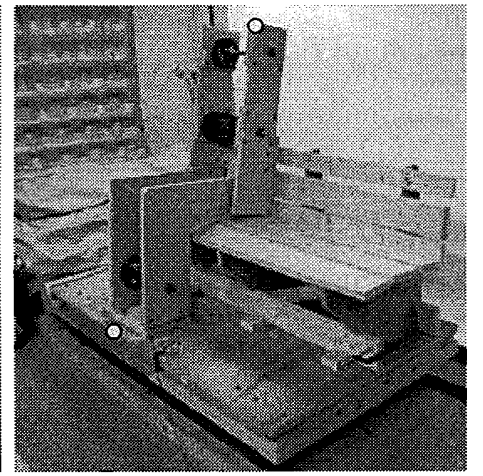

Fig.3 Experimental set up with a human body model and a long seat on an experimental carriage

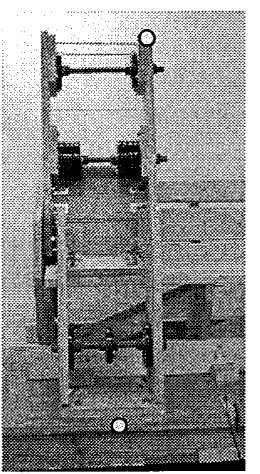

(b) With armrest

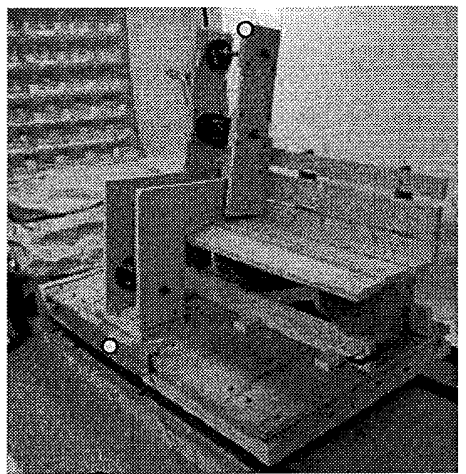

(c) Rear view of the case with wall

実験用の人体模型は，実験用の椅子に着座した成人男性を簡略化した形状で模擬するように，木材およびウェ イトをボルトで結合して作成した．初期状態で，人体モデルは椅子の座面および背もたれと接触している形状と した. 衝突時の挙動を再現することが実験の目的であるので, 人体の主要寸法(5), 体重, 重心, 回転慣性を再現 するように配慮し，人体全体の動きを再現できるようにするが，関節部は固定とするため関節の動きは再現する ことができない. 実験装置各部の質量と材料物性を Table1 に示す.

\section{$2 \cdot 3$ 実験の条件}

3 種類の座席に人体模型が着座する条件で各実験での衝突速度が一定となるように, 1 条件についてそれぞれ 5 回，合計 15 回の計測を行う．各条件で模型を含む台車質量が異なるために，落錪式の加速装置を使用し，使用す るおもりを一定とし，加速距離を調節して衝突時の速度が一定となるように工夫する.

\section{$2 \cdot 4$ 実験の結果と考察}

肘掛も壁もない条件を $\mathbf{N}$ ，肘掛けがある条件を $\mathbf{A} ，$ 壁がある条件を $\mathbf{W} と し て ，$ 実験で計測した台車床面中央 部着座した人体左頭頂部の衝突方向の変位を Fig. 4 に示す. Fig. 4 からわかるように，同一の実験条件での台車 および人体頭頂部の変位のばらつきはわずかである.Fig. 4 で確認できる台車の中央部で計測した台車と左頭頂 部の動きは以下の通り．ケース $\mathbf{N}$ では台車の動きは単純な反発，頭部は移動後反発はなくその位置で停留．ケー

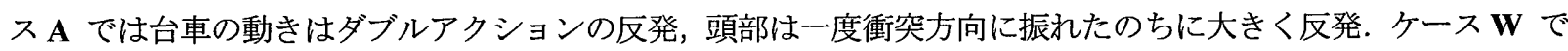
はケース $\mathbf{A}$ と類似しているが衝突の動き，反発の動きともやや少なめ.これは，人体の動きが台車およびロング シートを含む全体の挙動に影響を与えていることが理由の一つと考えられる. 


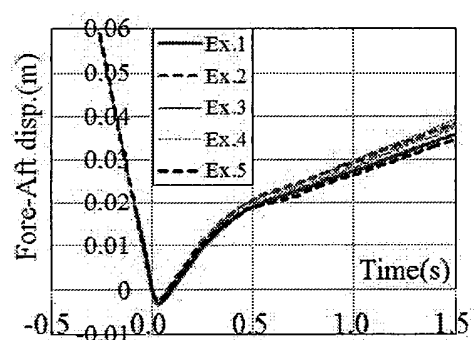

(a) Carriage Fore-Aft Case $\mathrm{N}$

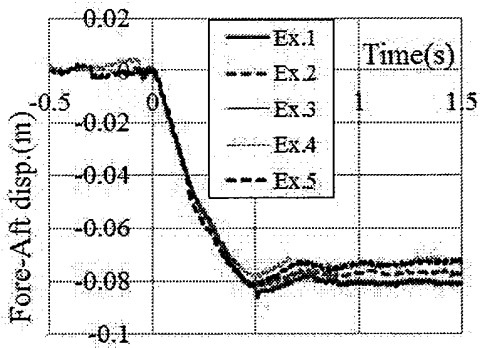

(d) Head Fore-Aft Case N

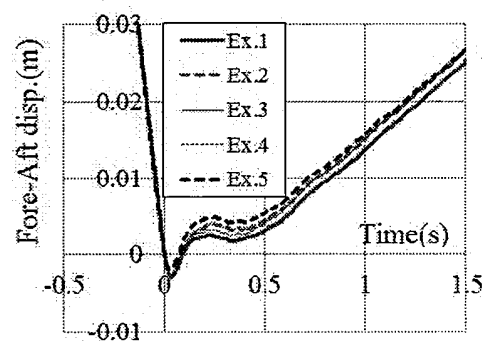

(b) Carriage Fore-Aft Case A

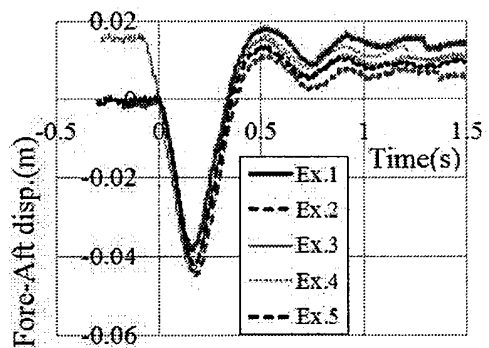

(e) Head Fore-Aft Case A

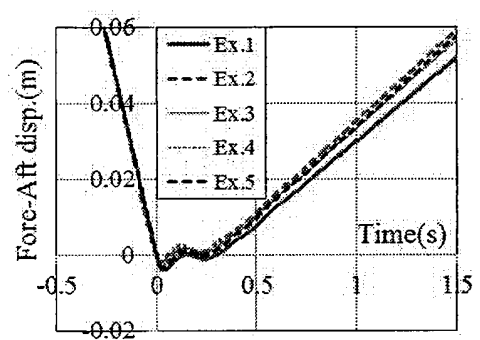

(c) Carriage Fore-Aft Case W

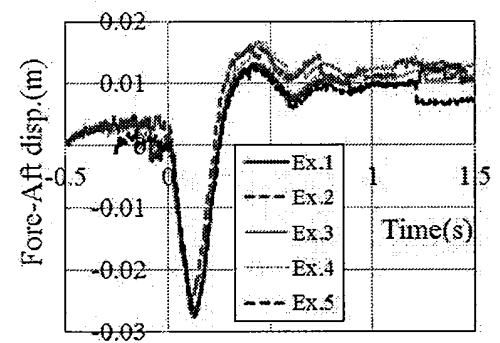

(f) Head Fore-Aft Case W

Fig.4 Experimental results of Fore-Aft isplacements of the carriage and the head by the carriage tests

\section{3. シミュレーション}

\section{$3 \cdot 1$ 目 的}

数值シミュレーションの結果は, シミュレーションモデルの作成方法, シミュレーション条件の設定により大 きく変化するため, 現実の衝突挙動を再現するためには, シミュレーションモデルの作成方針はもとより, 実験 結果との比較によってパラメータの設定を行う必要がある. ここでは, 数值シミュレーションの精度確認を目的 として衝突実験の数值シミュレーションを実施する.

\section{$3 \cdot 2$ シミュレーションモデル}

衝突実験に影響を及ぼすと考えられる要因を網羅するように，シミュレーションモデルを作成する．直接衝突 する台車（椅子および人体を含む）およびストッパーと一体化した基礎はもちろんであるが, 衝突時に基礎自体 が動くことも考慮して, 基礎を土台上に接触する状態で載せ, 条件を満たせば基䃈が動きうるようにする.また, 基礎が台車の進行方向に研究室の壁で支えられていることを表すために, 基礎の前端と後端で土台に接触した状 態で載っている架空の壁を作成し, 衝突時に架空の壁が移動することにより台車の運動エネルギーの一部が吸収 されるようにする. この時の壁の質量と, 壁と土台の間の摩擦係数は架空の存在であるために, いずれも実験結 果を再現できるように設定する. 台車は, 基礎の上面と接触しながら走行するが, 走行時の抵抗は台車のみの走 行実験を行って, 時間とともに減少する速度の計測結果から台車と基礎の上面の間の摩擦係数を設定する. ただ

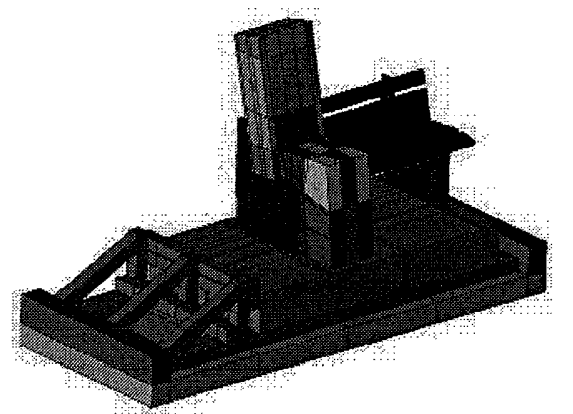

(a) Bird eye view of the case $\mathrm{N}$ (without armrest)

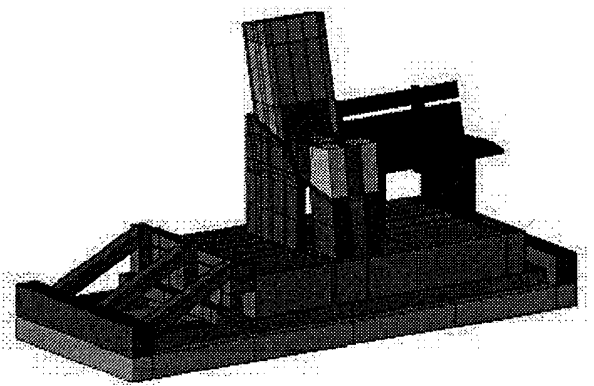

(b)Bird eye view of the case A(with armrest)

Fig.4 Simulation models with a human body model and a long seat on an experimental carriage 
し，木材で製作した基礎と研究室内の二重床の上面との摩擦係数は計測されていないため，この数值も実験結果 を再現できるように設定する，座席モデル，人体モデルは実験用模型と同じ質量，重心，回転慣性を有するよう に作成する. モデルの形状, 仕様を Fig.1, Fig.2, Table1, Table2に示す.

Table 1 Mass and material properties of parts

\begin{tabular}{|l|c|c|c|}
\hline Part & Mass $(\mathrm{kg})$ & $\mathrm{E}(\mathrm{Pa})$ & $v$ \\
\hline Human Body & 65 & $1.00 \mathrm{E}+09$ & 0.3 \\
\hline Long Seat & 46 & $1.00 \mathrm{E}+09$ & 0.3 \\
\hline Armrest & 6 & $1.00 \mathrm{E}+09$ & 0.3 \\
\hline Wall & 24 & $1.00 \mathrm{E}+09$ & 0.3 \\
\hline Carriage & 168 & $1.00 \mathrm{E}+10$ & 0.3 \\
\hline Base and Stopper & 103 & $1.00 \mathrm{E}+10$ & 0.3 \\
\hline Front Wall & 390 & $1.00 \mathrm{E}+11$ & 0.3 \\
\hline
\end{tabular}

Table 2 Frictional coefficients of sliding interfaces

\begin{tabular}{|l|c|}
\hline \multicolumn{1}{|c|}{ Surfaces } & Coefficient \\
\hline Human body-Carriage & 0.3 \\
\hline Human body-Long seat & 0.3 \\
\hline Carriage-Base & 0.004 \\
\hline Carriage-Stopper & 0.3 \\
\hline Base-Foundation & 1.0 \\
\hline Base-Front wall & 0.1 \\
\hline Front wall-Foundation & 1.0 \\
\hline
\end{tabular}

\section{$3 \cdot 3$ シミュレーションの条件}

本報告では, まずNのケースについて，実験結果を数值シミュレーションにより台車の挙動を再現することを 目的とする. 従って, 実験で $\mathbf{N} の 5$ 回の結果のうち, 平均的な挙動を示す 1 ケースを取り出し, 実験時に計測さ れた衝突速度を与えて, 衝突前後の台車の挙動について，計測值をシミュレーションの結果で再現する. 次に, 同じ実験結果の台車以外の計測項目について, 数值シミュレーションの結果と比較し, 再現されているか否かを 確認する. 最後に， $\mathbf{N}$ のケースで使用したシミュレーションの条件をそのまま $\mathbf{A}$ と W のケースに流用して，実 験結果が再現できているかを確認する.

\section{$3 \cdot 4$ シミュレーションの結果と考察}

シミュレーションの結果をFig. 5 に実験結果の代表例と比較して示す. N のケースでは台車, 人体の左頭頂と もに比較的よく実験結果を模擬しているが, $\mathbf{A}$ と $\mathbf{W}$ のケースではいずれも台車衝突時のダブルアクションが見ら れず，実験結果に比較して反発が大きい．これは， $\mathbf{N} の ケ ー ス て ゙ は な く ， \mathbf{A ~ と ~} \mathbf{W}$ のケースで存在する时掛，およ び壁のモデル化の影響によるものと考えられる.

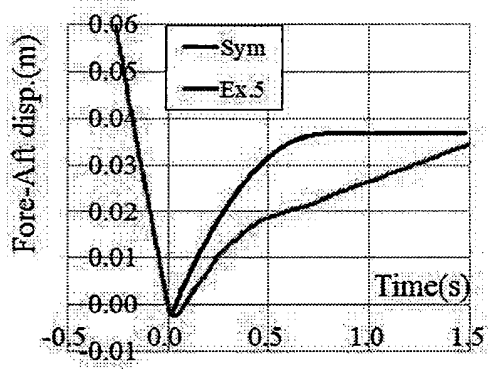

(a) Carriage Fore-Aft Case $\mathrm{N}$

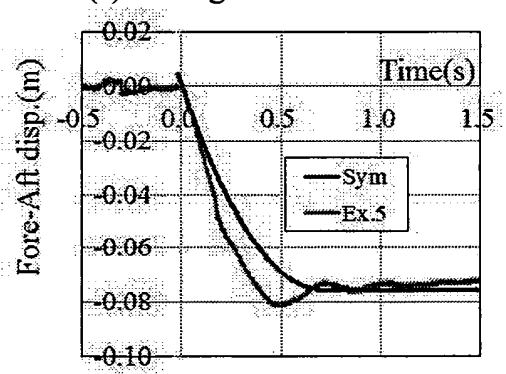

(d) Head Fore-Aft Case $\mathrm{N}$

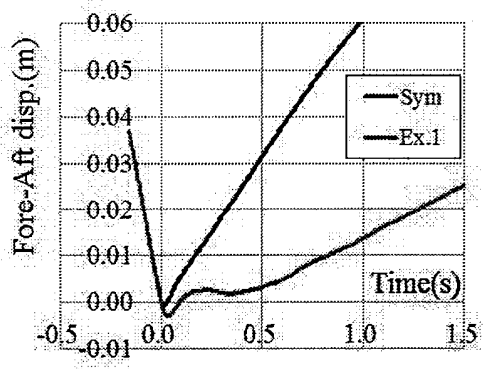

(b) Carriage Fore-Aft Case A

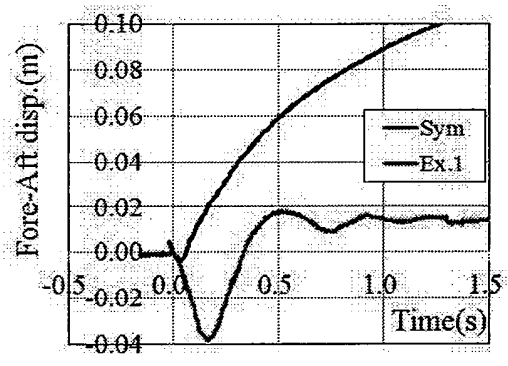

(e) Head Fore-Aft Case A

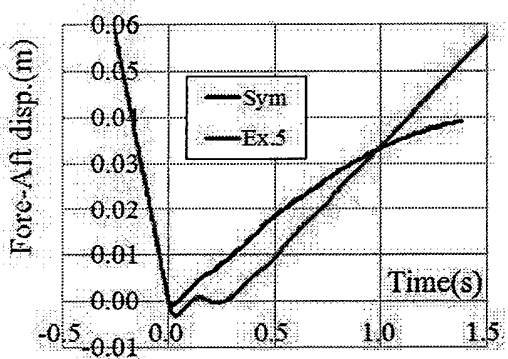

(c) Carriage Fore-Aft Case W

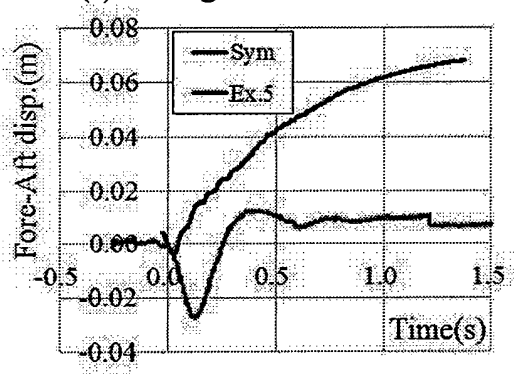

(f) Head Fore-Aft Case W

Fig.5 Comparison of Fore-Aft displacements between the simulated and the experimentally measured results

\section{4. 考 察}


シミュレーションにより模型を用いた台車実験の再現を目指した。Nのケースは衝突後に人体がロングシート 上を滑るという比較的単純な挙動であり、シミュレーションでほぼ再現することができた。 A と W のケースでは、 台車および人体頭部の挙動も実験結果と異なる結果を示した。これらの結果から、肘掛と壁を除く台車、土台、 基礎、人体などの材料物性や摩擦係数などはほぼ妥当な值が同定できたが、肘掛、壁の挙動挍よび人体との相互 作用については更に検討する余地があると考えられる。

特に、A と W のケースで実験では台車でダブルアクションの動きがみられたことは、时掛と壁がロングシート や台車と一体として挙動していないことを示唆している。今回のシミュレーションモデルでは肘掛と壁はロング シートと一体化したモデルとなっており、この点を改良する必要がある。

\section{謝辞}

本研究は, 近畿大学生物理工学部戦略研究補助金を受けて実施したものです.また, 実験装置の設計, 製 作および実験の実施にあたって協力していただいた卒業生諸氏に深く感謝いたします。

\section{文献}

(1) 小美濃,白戸,田中,(1999)."列車衝撃時の乗客挙動推定 (特集:人間科学)" , 鉄道総研報告,vol.13, No.11,pp27-32

(2) 渁江唯司ら(2012) "衝突時のバス乗客の転倒挙動を模擬する台車実験計測",機講論 J121013

(3) Shibue,et.al.,(2012) "Falling behavior simulation of a standing human body on a carriage at experimental collision, to simulate a collision between a high speed ship and a quay ", Proc.ISOPE, Vol.4,pp747-752

(4) 日本総合研究所(2007)."LS-DYNA v971 User's Manual"

（5）河内まき子・持丸正明，“2005 AIST 人体寸法データベース “, 産業総合研究所 H16PRO 287 